\title{
Effects of rail stations at airports in
}

\section{Europe}

paper submitted for presentation and publication at the 79th Annual Meeting of the Transportation Research Board, Washington, D.C., 8-13 January 2000

\section{Working Paper}

Author(s):

Widmer, Jean-Pierre; Hidber, Carl

Publication date:

2000

Permanent link:

https://doi.org/10.3929/ethz-a-004363260

Rights / license:

In Copyright - Non-Commercial Use Permitted

Originally published in:

Arbeitsberichte Verkehrs- und Raumplanung 13 
Paper No. 00-0222

\section{EFFECTS OF RAIL STATIONS AT AIRPORTS IN EUROPE}

Paper submitted for presentation and publication at the $79^{\text {th }}$ Annual Meeting of the Transportation Research Board, Washington, D.C., 8-13. January 2000

JP WIDMER AND C HIDBER

IVT

ETH

Zurich

Tel.: +41-1-633 3088

Fax.: +41-1-633 1057

widmer@ivt.baum.ethz.ch 


\title{
Effects of rail stations at airports in Europe
}

\author{
JP Widmer and C Hidber
}

IVT

ETH

Zurich

\section{AbSTRACT}

The paper discusses the effects of rail stations (and High-Speed Rail, HSR) at airports in Europe using a cost-benefit framework. Background for the work is the European Union (EU)-supported research Action COST-318, chaired by the Institut für Verkehrsplanung, Transporttechnik, Strassen- und

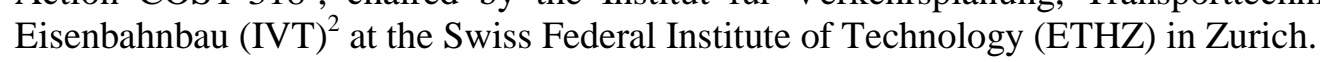

Rail stations are operational at many European airports. Rail stations at airports are at the centre of interest when considering road access relief at airports, as well as when considering rail and air transport complementary.

At a time when public budget deficits are under more scrutiny than in the past, and when the privatisation of state-owned public transport companies is being considered, it is of interest to know, to what extent rail stations at airports improve performance of the rail companies and to what extent they have a positive impact on the economy as a whole. The study based on cost-benefit analysis is a series of seven studies of rail stations at major (Brussels, Zurich, Frankfurt, Paris-Orly and ParisCDG2) and medium-sized (Geneva, Stuttgart) airports.

The case study results (Belgium; France; Germany; Switzerland) with their large spectrum of technology and operating system backgrounds showed:

- the effects on national economy while taking into account the investment costs and on the railways are positive for major (hub) airports, except for Brussels and Paris-Orly for particular reasons, and balanced or negative for the medium-sized airports analysed.

- the results are related not only to airport size, but also to the average access distance to the airport by rail, as users' benefits in time and fare savings have a significant role.

- the effects on public transport as a whole (all public transport companies at the airport, including taxi and parking operators) are negative.

\section{KEYWORDS}

Airport access - rail - cost-benefit analysis - Europe - case studies - COST

\footnotetext{
${ }^{1}$ COST, European Co-operation in the field of Scientific and Technical Research. For more details see the final report of the Action COST-318 (1998).

${ }^{2}$ Institute for Transport Planning, Transport Technology, Highway and Railway Engineering.
} 
European airports have provided ground access by rail for nearly four decades with an ever-increasing number of airports adopting such services. This paper analyses the costs and benefits of rail access, both conventional and high-speed rail (HSR), for a number of cases. The paper is based on the work of the European Union (EU)-supported research initiative COST-3181, which was chaired by the Institut für Verkehrsplanung, Transporttechnik, Strassen- und Eisenbahnbau (IVT) of the ETH Zurich. In Europe the provision of rail access to airports relies on the fact, that most of the commercial airports of relevance are situated (within or) close to agglomerations. Furthermore, there is a large and often dense railway network within (Underground) and around (state railways) those agglomerations, and that train frequencies are good.

For airport access road transport is normally the only form of ground transport with a door-to-door capability. This is particularly welcome for air passengers having to reach or arriving at an airport with (heavy) luggage. However, the use of private cars leads to substantial costs for the local road authorities and the airport operator in the form of large parking facilities and drop-off and pick-up areas. In addition, the use of cabs or kiss-and-ride opportunities leads to an intensive use of the road access facilities at the airport and/or sensitive (sub-) urban corridors. Congestion at the airport or on the access roads makes it difficult for air travellers to ensure their timeliness without accepting a disproportional safety margin.

Airport rail access takes advantage of the specific advantages of rail transport over the car. These advantages differ for the various actors, such the railway operators, the air travellers, the airport employees, the airport operators and the general public. These advantages may be summarised as follows: high volumes of transport per time unit, which, associated with high departure frequencies, provide a large capacity reserve, with little need for (parking) space at the airport. Furthermore, departure and arrival times are scheduled, reducing the time margins, which need to be accepted.

Moreover, rail transport has an acknowledged lead in terms of safety and in terms of air pollution over (private) road transport. There is also some expectation, that airport rail transport could reduce public subsidies for the railways at least in the long term.

Railway companies operating at airport rail stations may benefit from additional revenue resulting from substantial volumes of additional passenger traffic. This might not necessarily be true for other

\footnotetext{
${ }^{1}$ COST, European Co-operation in the field of Scientific and Technical Research. For more details see the final report of the Action COST-318 (1998).

${ }^{2}$ Institute for Transport Planning, Transport Technology, Highway and Railway Engineering.
} 
(public) transport companies, nor for other activities related to airport (ground) access, which will be challenged for market share, e.g. taxis, van pools, express buses, local buses etc.

Rail stations are now operational at many European airports. Such stations are of particular interest, when discussing potential synergies between (high-speed) rail and regional air services, either as a feeder to long-haul-services or as direct replacements.

The first examples started as shuttle services between the airport and the city centre, often the main railway station, where connections with the general railway network, as well as with the (underground) urban public transport system were offered (see Table 1). The Brussels airport rail link, for example, was put into service in time for the World Exhibition in 1958 and aimed at relieving the then increasingly congested local road access to the airport. Currently the road access situation at the Brussels airport has worsened again.

The concept of the airport rail link then developed as an alternative and a challenger to road transport as a whole. As a result, the airport stations were fully integrated as part of the relevant suburban and national railway networks. When enabling a stop of long-distance trains at the airport, such as, for example, at Amsterdam, Frankfurt, Geneva or Zurich, not only the airport vicinity is connected by rail, but also (with no change) the surrounding larger cities within the region.

In 1994, the first airport stations fully integrated into the national HSR systems went into operation (Paris-Charles de Gaulle (CDG2) and Lyon-Satolas). The next example of this type will be Frankfurt/ Main airport, where a second rail station is being built, which is part of the high-speed rail link between Frankfurt and Cologne. HSR access primarily aims to extend the airport catchment area for a given acceptable access time.

The latter aspect is relevant. HSR services may be seen as an alternative and challenge to the regional feeder flights at the increasingly congested main airports as air transport liberalisation and competition lead Europe-wide to a concentration of air transport activities at some airports due to the development of hub-and-spoke systems by many airlines (The third Package on air transport liberalisation within the European Union was implemented step by step from 1993 to 1997. Full cabotage rights were granted in 1997).

While the provision of rail access is popular with travellers and airports, this paper aims to understand, whether such rail access is beneficial to society as a whole, as measured through a suitable cost-benefit analysis, including the relevant monetary costs, but also health, safety and environmental effects. 
Table $1 \quad$ Types and examples of airport rail access

\begin{tabular}{|c|c|c|}
\hline Type of link & Classical & High-speed rail \\
\hline City-centre to airport & $\begin{array}{l}\text { Brussels } \\
\text { London-Heathrow } \\
\text { London-Stansted } \\
\text { Newcastle } \\
\text { Paris-CDG } \\
\text { Paris-Orly } \\
\text { Milan-Malpensa } \\
\text { Madrid } \\
\text { Stuttgart } \\
\text { Munich }\end{array}$ & Oslo-Gardermoen \\
\hline Sub-urban and inter-regional rail system at airport & $\begin{array}{l}\text { Amsterdam } \\
\text { Geneva } \\
\text { Zurich } \\
\text { London-Gatwick } \\
\text { Birmingham } \\
\text { Frankfurt }\end{array}$ & $\begin{array}{l}\text { Paris-CDG } \\
\text { Lyon-Satolas } \\
\text { Frankfurt }\end{array}$ \\
\hline Airport to airport & Zurich to Geneva & $\begin{array}{l}\text { Paris CDG to } \\
\text { Lyon -Satolas }\end{array}$ \\
\hline
\end{tabular}

2 MeTHODOLOGY

The method chosen to assess whether rail stations at airports are beneficial or not to the economy as a whole was a cost-benefit analysis (CBA) (Mishan, 1975) formulated for the specific assessment problem at hand. In a cost-benefit analysis the costs and benefits of the project studied will be compared over the period of its economic life including the construction and planning period. Each item of the costs, revenues and benefits is valued each year as the difference between the situation with the new infrastructure and the "status quo ex ante" on the other side, that is the situation which would have prevailed if the new infrastructure had not been built (see Figure 1). The difference ("saldo") will be discounted, using a suitable rate, normally the one applied for public works by official agencies. Inflation is excluded from this rate whenever the saldo is given for the year of reference (see Figure 1).

The decision criteria are based on sums of the discounted amounts. They determine whether the new infrastructure generates (or is about to generate) gains or losses for society. When considering the influence on public transport (accounts), only parts of the cost and benefit items need to be considered. 
Figure 1 Basic idea of the CBA- approach

\section{development \\ value}

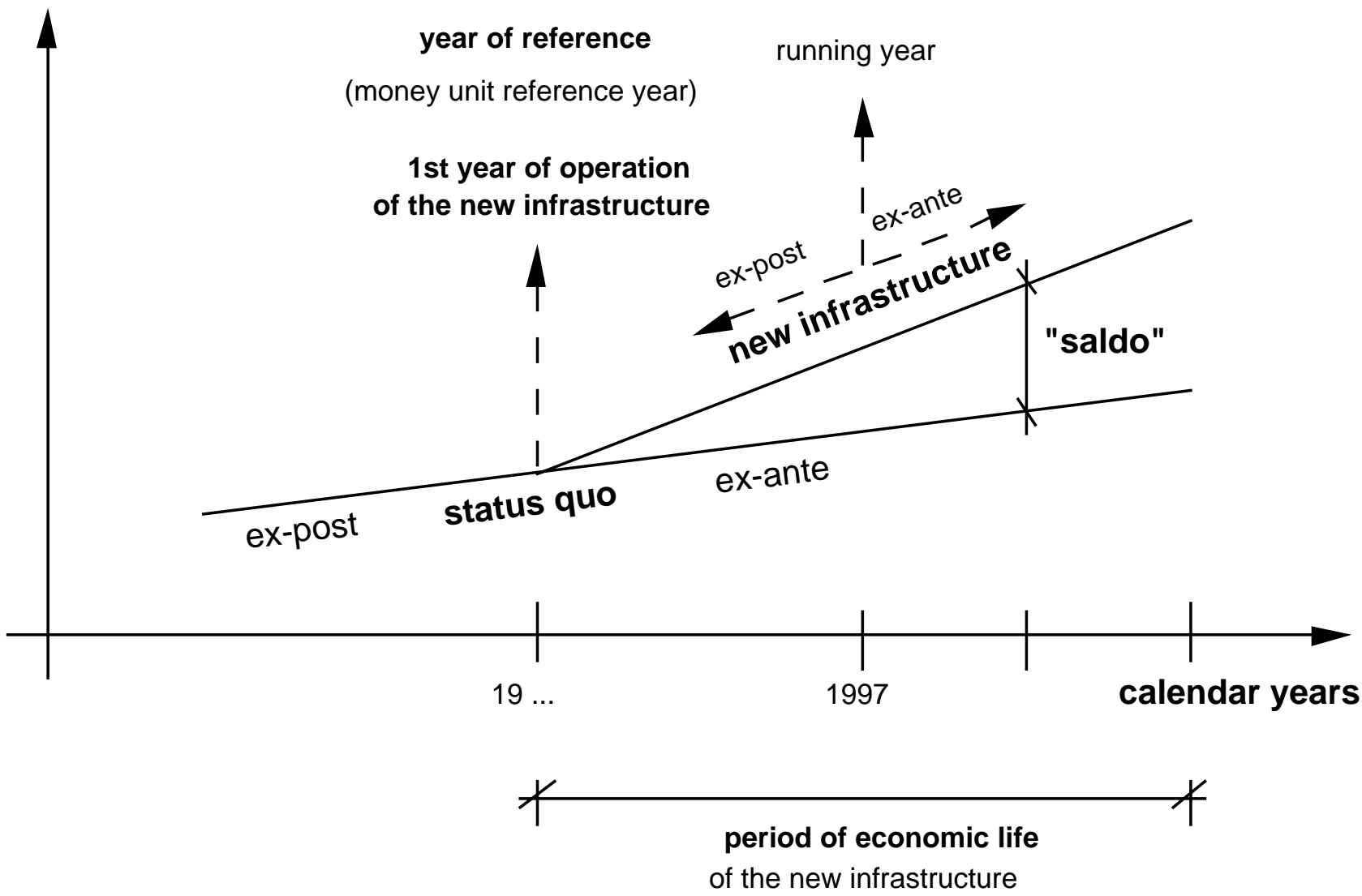

For this study the year of reference was conveniently chosen as the year of the end of the construction period and the start of the operation of the new infrastructure. The average economic lifetime was not assessed by the technical lifetime of the new infrastructure, but by the economic one, after which no residual value of the investments needs to be taken into account

The average lifetime of the whole new infrastructure is calculated as a cost share weighted average of the amortisation annuities for each type of infrastructure element (overall, civil engineering, track, equipment and installations) with their usual renewal period. Considering yearly equal amortisation amount and discount rate:

$$
\begin{aligned}
& \text { for a part of the new infrastructure: } \quad a_{g}=\frac{p(1+p)^{n_{g}}}{(1+p)^{n_{g}-1}} \\
& \text { for the whole new infrastructure: } \quad A_{n}=\frac{p(1+p)^{n}}{(1+p)^{n}-1}=\frac{\sum a_{g} * K_{g}}{K}
\end{aligned}
$$


years of economic life: $\quad \mathrm{n}=\frac{\ln \left(\mathrm{A}_{\mathrm{n}} /\left(\mathrm{A}_{\mathrm{n}}-\mathrm{p}\right)\right)}{\ln (1+\mathrm{p})}$

where: $\quad \mathrm{p}$ : discount rate;

$\mathrm{n}_{\mathrm{g}}$ : lifetime of a part of the new infrastructure;

$\mathrm{a}_{\mathrm{g}}$ : annuity for a part of the new infrastructure;

$\mathrm{n}$ : lifetime of the whole new infrastructure;

$\mathrm{K}_{\mathrm{g}}$ : cost of part ,"g" of the new infrastructure part;

$\mathrm{K}$ : cost of the whole new infrastructure;

$\mathrm{A}_{\mathrm{n}}$ : annuity for the whole new infrastructure;

The social (official) discount rate for the relevant country was used (3\% in Germany, 4 to $6 \%$ in Switzerland; $8 \%$ in France). The choice of the discount rate has severe implications for the conclusions with high discount rates favouring staged investments and low initial investments. Inflation as been considered, taking into account the officially published rates, such as the national construction cost index for infrastructure costs (see Figure 1).

As part of this study the following costs and benefits were calculated and estimated from the available sources:

\section{- Investment costs:}

- by calendar year of construction, in order to be able to discount the amounts easily (properly considering inflation)

- by type of element of the new infrastructure in order to account for the different periods of economic lifetime.

\section{- Operators' surplus (or shortfall):}

- Investment costs before and (cost savings) within the economic lifetime of the new infrastructure. For instance the rolling stock of shuttle rail services was considered fully, while the stock of main line services was not considered. Investment cost savings may arise from, for example, no or reduced further investment in car parking facilities.

- Operators' costs before and (cost savings) within the economic life of the new infrastructure. The same examples as for the investment costs can be used; moreover, operating cost savings are expected for taxi-cabs, but not necessarily if the airport is a terminal for local/ regional bus services, which may not be changed as a result of the rail services.

- Operators' revenues before and (revenue shortfalls) within the economic life of the new infrastructure; rail transport will benefit from the users' shift from other airport access modes, including taxicab and parking facilities operators. Where no detailed figures were available, estimates were based on operating costs, average earnings and traffic volumes

- Energy tax losses for the government, due to the users' shift from car to train;

- Users' surplus was calculated using a specially developed computer programme (Abay, 1984a) calculations were based on known traffic volumes by access distance and mode of 
access, average speed and cost by car; timetables and fares of all modes of public transport, share of season-tickets, estimated shares for travel purpose (professional/ non-professional) for air passengers and other users (employees, visitors, escorting persons), and values of time for travel time savings by purpose.

\section{- External costs:}

- Noise: it was assumed that noise protection measures along the rail line restore the situation quo ante, i.e. before the new infrastructure operated, which are included in the investment costs; car noise reduction due to the users' shift to airport rail access was not considered as relevant

- Air pollution: it was assumed that electrical power production is "clean“ due to technology improvements, at least that the air pollution due to trains is irrelevant compared to that due to cars. Reduced car emissions are considered and valued in line with relevant studies on the consequences of road traffic pollution (see Ecoplan, 1992)

- Accidents: unit costs are taken from relevant studies on the consequences of road traffic safety (see e.g. Deffke, Köppel and Meeves, 1995)

- Other costs and benefits, such as comfort and convenience were ignored.

Given the European background of COST Actions and therefore the very much-appreciated opportunity to obtain the relevant data, the study was able to include seven cases. The following sections briefly describe the different cases (see Table 2):

Table 2 Characteristics of the airports and rail links

\begin{tabular}{|c|c|c|c|c|c|c|c|}
\hline Item & ZRH & GVA & STR & FRA & BRU & CDG & ORY \\
\hline \multicolumn{8}{|l|}{ Airport: } \\
\hline Medium-sized & & $\mathrm{X}$ & $X$ & & & & \\
\hline Major hub & $\mathrm{X}$ & & & $\mathrm{X}$ & $\mathrm{X}$ & $\mathrm{X}$ & $\mathrm{X}$ \\
\hline Hub for & Swissair & & & Lufthansa & SABENA & Air France & Air France \\
\hline Total Air passenger volumes (Mio) in 1998 & 19.3 & 6.4 & 7.2 & 42.7 & 18.5 & 38.6 & 25.0 \\
\hline \multicolumn{8}{|l|}{ Type of rail link at the airport: } \\
\hline City-centre shuttle service & & $(\mathrm{X})$ & & & $\mathrm{X}$ & & \\
\hline Non-conventional to close suburban rail station & & & & & & & $\mathrm{X}$ \\
\hline Suburban rail system & $X$ & & $X$ & $X$ & & $X$ & \\
\hline Inter-city rail system & $\mathrm{X}$ & $\mathrm{X}$ & & $\mathrm{X}$ & $(\mathrm{X})$ & & \\
\hline High-speed rail system & & & & $(\mathrm{X})$ & & $\mathrm{X}$ & \\
\hline Rail passengers(*) getting off/ on (Mio) in 1998 & 8.6 & 2.1 & 1.3 & 4.7 & 2.7 & 8.0 & 1.9 \\
\hline \multicolumn{5}{|c|}{$\begin{array}{l}(*): \quad \text { at STR }(1997) \text { and FRA air passengers by rail only } \\
\text { X. }\end{array}$} & & & \\
\hline
\end{tabular}




\subsection{Zurich (ZRH)}

The Zurich-Kloten (ZRH) airport is situated $11 \mathrm{~km}$ North of the city-centre of Zurich and has two contiguous terminals. The airport is home base and hub for Swissair. The airport is connected to the city by motorway and to the long-distance road network. There are several bus lines connecting the airport with suburban centres.

The Zurich airport rail access is a $6 \mathrm{~km}$ long new, mostly underground double-track deviation from the old rail line connecting Zürich-Oerlikon with Winterthur, which is part of the main East-West corridor across Switzerland. It was put into operation in 1980 with local and Inter-City (IC) trains that fully replaced the Swissair bus shuttle between the main station in the city-centre and the airport. About 9 Mio passengers/year are getting on/off at the airport rail (through) station currently. It ranks among the country's top ten in terms of revenues and traffic volumes. Not less than 290 train departures a day are serving most of suburban Zurich and the nation-wide network of the Swiss Federal Railways, plus destinations abroad, such as Munich.

\subsection{Geneva (GVA)}

The single-runway and terminal Geneva-Cointrin (GVA) airport is situated only 4km Northwest of Geneva city-centre. The airport is the main airport for the Western (French-speaking) part of Switzerland, as well as for the French Alps region which accounts for about one-fifth of the airport catchment area in terms of passengers. Since all but one Swissair long-haul flights were moved to its Zurich hub, frequencies to neighbouring major hub airports (London, Paris, Frankfurt, Amsterdam and Brussels) increased significantly. The GVA airport is connected by the motorway to the dense Swiss and French Alps motorway networks. There are currently two urban bus lines stopping at the airport.

The Geneva airport rail access is a 6-km long double-track ( $2.5 \mathrm{~km}$ newly built and $3.5 \mathrm{~km}$ upgraded) from Geneva main station and was built between 1982 and 1987. The Swissair bus shuttle between Geneva main station and the airport, as well as a bus service from the airport to the city of Lausanne were then cancelled. The underground (dead-end) Geneva airport rail station was put into service mid1987 serving as western terminus of the main IC railway East-West corridor crossing Switzerland. It serves little more than 2 Mio passengers getting on/off a year, with 86 train departures a day, covering most of the Swiss Federal Railway network and including destinations abroad, such as Milan, but for the time being there is no direct link to the French railway system and its High-Speed Rail (TGV) System from the airport. Exploiting the gap between the arrival and departure times at the airport station inherent in the fixed-headway timetable operated, some Inter-city trains ride back as local trains to the city before returning to the airport. The airport rail station is also that of Palexpo, a large exhibition complex. 


\subsection{Stuttgart (STR)}

The single-runway and terminal complex Stuttgart-Echterdingen (STR) airport is situated $14 \mathrm{~km}$ South of the Stuttgart city-centre. The airport is the main airport in the southwestern corner of Germany. The STR airport has in particular direct access to the main West-East motorway Karlsruhe-München. Currently three (sub-) urban bus lines stop at the airport.

The newly built $8 \mathrm{~km}$ track branch of the main rail line Stuttgart-Italy and is part of the $20 \mathrm{~km}$ long rail link from the Stuttgart main station to the airport (served by 72 train departures weekdays and 39 on a weekend day). It was built between 1983 and 1993 and put into operation in 1993 as a dead-end railway line at the airport, which about one and a half Mio air passengers are currently using per year. The bus shuttle between the Stuttgart city-centre and the airport then went out of operation. As the newly built airport rail link is also dedicated to connect suburban destinations with the city of Stuttgart, both the full and a partial allocation of the infrastructure costs had to be considered. An extension beyond the airport is foreseen, depending on the construction and location of a new highspeed rail line between Stuttgart and Ulm (München).

\subsection{Frankfurt (FRA)}

The Frankfurt Rhein/Main (FRA) airport is situated $11 \mathrm{~km}$ Southwest of the city-centre of Frankfurt and has two terminal complexes linked by a people mover. The airport is the home base and main hub for Lufthansa. The FRA airport is close to the interchange of two major North-South and East-West motorways. There are at the moment several (low-frequency) bus lines connecting FRA with centres within the airport catchment area.

The $11 \mathrm{~km}$ long rail access from the Frankfurt city-centre main station to the airport (currently served by 176 trains per day on average), of which $6 \mathrm{~km}$ were newly built as a deviation from the rail line to Wiesbaden and Mayence, was under construction between 1969 and 1972 and put into operation with local trains in 1972. Airport express bus shuttle services ceased operating. An upgrading of the airport rail services to Inter-City rail operations occurred in 1985. The airport rail (through) station has currently almost 5 Mio air passengers getting on/off a year. A new station with direct HSR operations lies a few months ahead, extending the ground access catchment area of the Frankfurt airport significantly, so that some air feeder services, such as those from Cologne, are to be shut down.

\subsection{Brussels (BRU)}

The Brussels-Zaventem (BRU) airport is situated 12km Northeast of the city-centre of Brussels and has a new terminal and a contiguous old one, which is currently being up-graded. The airport is home 
base and hub for SABENA. The BRU airport is connected to the Brussels agglomeration by the "Ring" motorway to the long-distance road network. There are for the time being several (lowfrequency) bus lines, for instance to Antwerp.

The $18 \mathrm{~km}$ long rail link from the Brussels main railway station to the airport, of which $3 \mathrm{~km}$ are a dead-end track from the main railway line Brussels-Liège-Cologne (Germany), was put into operation in 1955. Until 1960, the existing bus link to the airport was operated in parallel with the railway service from the city-centre rail stations. From the beginning of the World Exhibition in 1958 the train service was fully operational as a shuttle service to the city centre main stations. In the first years, the rail link to the airport was operated three times an hour, with a bus service in the late evening; later on, it was reduced to twice an hour; the frequency now is once again trice an hour. Since 1998 a new airport rail station is in service and designed to be converted to through-operations in a second development stage. It has currently almost 3 Mio passengers getting on/off a year.

\subsection{Paris (CDG2)}

The Charles de Gaulle (CDG) airport is situated in Roissy, 26km North- East of Paris, and consists of two main terminals, ignoring a smaller charter terminal. The CDG airport is connected to Paris by the motorway and to the long-distance road network. From the city-centre of Paris to CDG there are two direct Air France coach lines, as well as a bus line operated by RATP, the regional public transport provider, as "Roissy-bus". Besides, an RER-link (the rapid suburb "B" line, underground through the city of Paris) exists. It terminated between the terminals before the new rail station (called "CDG2") under airport terminal 2 (and its extensions) was built. At that time, the passengers could use a busshuttle service between the (former) RER station (now called "CDG1") and airport terminal 2.

The new rail station at terminal 2 (CDG2) is situated on the Paris agglomeration high-speed rail bypass linking the TGV "North", "Southeast" and "Atlantic" high-speed rail connections, and offers also direct connections with the RER "B" extension (providing also secondary access to some locations within the Paris agglomeration, such as the Parc des Expositions). The bus-shuttle service from the former RER station to airport terminal 2 has closed down as a consequence. The RER trains operate about every 8 minutes. HSR services (TGVs) started calling at CDG2 in November 1994 with 9 pairs of through-high-speed trains, and since June 1996 with 18 pairs on a workday, indicating traffic growth with 1.3 Mio passengers served in 1998.

\subsection{Paris (ORY)}

The Orly (ORY) airport is situated 14km South of Paris and has two terminals. The airport is under an aircraft movement limitation rule, which limits its development. The ORY airport is connected to Paris 
by the motorway and to the long-distance road network. There is an Air France coach line from the city-centre of Paris directly to ORY, as well as a bus line operated by RATP as "Orly-bus". Besides, the RER "C" (the rapid suburb "C" line, underground through the city of Paris) is operated as "Orlyrail" with a bus-shuttle service to the terminals.

The new rail infrastructure operating since October 1991 is "ORLY-VAL", an automatic rail system (like that operating as public (underground) transport system in the cities of Lille and Toulouse) linking both airport terminals to the RER "B" station of Antony. The double track is $7.3 \mathrm{~km}$ long and the double-cab trains operate about every 8 minutes, serving about 2 Mio passengers a year. The economic life of this non-conventional system has been set as 15 to 20 years, but this range does not affect the results very much.

\section{$4 \quad$ RESULTS}

The study is limited to airport ground access. Welcome-if-feasible substitution effects of rail on air feeder services (as part of hub-and-spoke systems) were not taken into account. The main assumptions and inputs are presented in Table 3

Table 3 Main input variables and their values (at the start of rail operations)

\begin{tabular}{lrrrrrrr}
\hline Item & ZRH & GVA & STR & FRA & BRU & CDG2 & ORY \\
\hline Country & $\begin{array}{r}\text { Switzer- } \\
\text { land. }\end{array}$ & $\begin{array}{r}\text { Switzer- Germany } \\
\text { land }\end{array}$ & Germany & Belgium & France & France \\
Discount rate for public works & $4-6 \%$ & $4-6 \%$ & $3 \%$ & $3 \%$ & $(3 \%)$ & $8 \%$ & $8 \%$ \\
At the time rail operations started in & 1980 & 1987 & 1993 & 1972 & 1955 & 1994 & 1991 \\
Rail traffic volumes (in Mio/ year) & 3.8 & 2.2 & 1.6 & 4.6 & 0.3 & 2.2 & 1.2 \\
Rail share as airport access overall & $34 \%$ & $25 \%$ & $11-12 \%$ & $14 \%$ & $18 \%$ & $9 \%$ & $3 \%$ \\
Rail share among air passengers & $40 \%$ & $30 \%$ & $12-16 \%$ & $24 \%$ & unknown & $18 \%$ & $6 \%$ \\
Unit & & & & & & $(3 \%$ TGV) & \\
Value of time - working [h] & 19.80 & 27.00 & 32.57 & 12.82 & 39.00 & 76.05 & 69.29 \\
Value of time - non-working [h] & 11.40 & 15.50 & 18.85 & 7.42 & 22.50 & 44.03 & 40.12 \\
Accident cost rate per Pkm & 0.0115 & 0.0145 & 0.027 & 0.0125 & 0.065 & 0.089 & 0.084 \\
\hline
\end{tabular}

The case study results are presented at three levels: the railway entity, public transport as a whole and finally the national economy, including users' benefit and (avoided) external effects by the use of rail transport. Table 4 provides the numerical results using a uniform discount rate of $5 \%$ across all countries. Table 5 summarises the results qualitatively. For the details of calculations and assumptions see COST 318 (1998), Abay (1984b), Dasen and Widmer (1998), Gottwald, Schilling and Widmer (1998), Gottwald and Widmer (1998), Hintermeister and Widmer (1998) and Widmer and Abay (1993). 
Table 4 Monetary results of the seven case studies (Discount rate of 5\%)

\begin{tabular}{lrrrrrrr}
\hline Item & ZRH & GVA & \multicolumn{1}{c}{ STR } & FRA & BRU & CDG2 & ORY \\
\hline Estimated Economic lifetime [a] & 45 & 43.5 & 45 & 45 & 45 & 45 & 15 \\
Unit [Mio] in & CHF & CHF & DM & DM & BF & FF & FF \\
Based on prices of & 1980 & 1987 & 1993 & 1972 & 1955 & 1994 & 1991 \\
Investment costs & $\mathbf{- 4 7 1}$ & $\mathbf{- 3 3 4}$ & $\mathbf{- 2 2 2}$ & $\mathbf{- 1 1 8}$ & $\mathbf{- 1 8 0}$ & $\mathbf{- 2 0 7 4}$ & $\mathbf{- 1 2 5 0}$ \\
Effects on rail operations & 754 & 396 & 8 & 93 & -236 & 2368 & 93 \\
Effects on rail transport & $\mathbf{2 8 4}$ & $\mathbf{6 2}$ & $\mathbf{- 2 1 4}$ & $\mathbf{- 2 5}$ & $\mathbf{- 4 1 6}$ & $\mathbf{2 9 4}$ & $\mathbf{- 1 1 5 7}$ \\
Effects on other public transport & -541 & -388 & -93 & -214 & 34 & -1056 & -288 \\
$\quad$ Bus services & -372 & -15 & 2 & -134 & 55 & 0 & 0 \\
$\quad$ Taxi-cabs & -30 & -123 & -29 & -16 & -7 & -250 & -116 \\
$\quad$ Car-parking & -27 & -133 & -19 & -10 & -2 & -38 & 3 \\
$\quad$ Earning shortfalls from fuel tax & -112 & -117 & -47 & -54 & -12 & -768 & -175 \\
Effects on public transport & $\mathbf{- 2 5 8}$ & $\mathbf{- 3 2 6}$ & $\mathbf{- 3 0 7}$ & $\mathbf{- 2 3 9}$ & $\mathbf{- 3 8 2}$ & $\mathbf{- 7 6 2}$ & $\mathbf{- 1 4 4 5}$ \\
Effects on public transport new users & 284 & 131 & 83 & 102 & 5 & 232 & -38 \\
$\quad$ Working users & 202 & 77 & 46 & 60 & 4 & 141 & -18 \\
$\quad$ Non-working users & 82 & 54 & 38 & 42 & 1 & 91 & -20 \\
Effects on previous users & 458 & 156 & 111 & 566 & 38 & 1305 & -310 \\
$\quad$ Time savings & 239 & 105 & 42 & 391 & 38 & 1178 & 75 \\
$\quad$ Working users & 152 & 66 & 27 & 248 & 27 & 682 & 48 \\
$\quad$ Non-working users & 87 & 38 & 15 & 144 & 10 & 496 & 28 \\
$\quad$ Cost savings & 219 & 52 & 69 & 174 & 0 & 127 & -386 \\
$\quad$ Working users & 110 & 26 & 35 & 87 & 0 & 63 & -193 \\
$\quad$ Non-working users & 109 & 26 & 35 & 87 & 0 & 63 & -193 \\
Avoided external costs & 68 & 31 & 30 & 49 & 25 & 453 & 134 \\
$\quad$ Avoided accidents & 55 & 20 & 26 & 30 & 13 & 356 & 81 \\
$\quad$ Avoided pollution & 13 & 11 & 4 & 19 & 12 & 97 & 53 \\
Total & $\mathbf{5 5 2}$ & $\mathbf{- 8}$ & $\mathbf{- 8 2}$ & $\mathbf{4 7 7}$ & $\mathbf{- 3 1 7}$ & $\mathbf{1 2 2 8}$ & $\mathbf{- 1 6 5 8}$ \\
\hline & & & & & & &
\end{tabular}

Table 5 Qualitative assessment of the seven case studies

\begin{tabular}{lccccccc}
\hline Item & ZRH & GVA & STR & FRA & BRU & CDG2 & ORY \\
\hline Investment costs & - & - & - & - & - & - & - \\
Effects on rail operations & + & + & + & + & - & + & + \\
Effects on rail transport & + & + & - & $+/-$ & - & + & - \\
\& on other public transport & - & - & - & - & + & - & - \\
Effects on public transport & - & - & - & - & - & - & - \\
User benefits & + & + & + & + & + & + & + \\
Avoided external costs & + & + & + & + & + & + & + \\
Total & + & $+/-$ & - & + & - & + & - \\
\hline
\end{tabular}

+ : positive results, $-:$ negative results, $+/-$ : balanced results 
Taking into account the range of the discount rates applied (4 to 6\% with the exception of France where $8 \%$ is used) the following conclusions can be drawn:

- Overall results are mixed: major (hub, national airline home base) airports show positive overall results, except Brussels (BRU) and Paris-Orly (ORY) for particular reasons (see below), whereas those of medium-sized airports are balanced or negative;

- Avoided external effects (noise, air pollution, accidents) make throughout positive contributions in line with the expected advantages of rail transport.

- User benefits as far as those converted into monetary value (time and travel expense reductions) are positive, except for Paris-Orly (ORY).

- Effects on other public transport services, as well as the effects on public transport as a whole show negative values; the reason being that other public transport modes loose transport demand (earnings) to rail without saving costs, as they are provided at a same level of service. The exception of Paris-CDG2 is due to demand shifts to the busses from car drivers given the extreme level of congestion in Paris and the direct services from the west of Paris not directly served by the RER-connection.

- Effects on rail transport are positive as far as the operating results are concerned, except Brussels (BRU). Including the investment costs of the new infrastructure, they show positive results for the TGV rail station in Paris-CDG2, the Swiss cases and nearly so in the Frankfurt (FRA) case, which might be due to the delayed arrival of national services at the Frankfurt airport. Clearly, national and HSR services tilt the balance of cost and incomes in favour of rail. A strongly contributing factor is, of course, when, as often in Europe, a rail (network) operation close to the airport exists (reducing investment costs) and when direct rail network and HSR stops at the airport are supplied (extending the airport catchment area significantly, both for the airport and the rail operator);

The Brussels airport case is a specific one, as the existing airport rail access was the first on the European continent and the of economic life of the existing rail access infrastructure, as defined in the study, is coming to an end. The Belgian analysis stressed, that there was no possibility to verify the data used for the 1950s and early 60s, that is the construction period and the first years of operation, which were derived from an incomplete documentation in UIC and EARB (1964). Estimates of order of magnitude by SNCB have shown however, that values used should be plausible. The poor costbenefit result can be explained by the following three factors:

- The airport rail access was put into service at a time as air transport was by no means mass transport, but generally used by only few passengers resulting in high rail operating costs compared to those of the replaced bus services due to the initially low demands;

- As the existing rail service is a shuttle to the city-centre, the time savings (as part of the users' surplus) are small in comparison to other modes, in particular for rail passengers connecting in the city-centre;

- Rail revenues were (very) low due to the generally low Belgian fares, as no premium was charged for the services.

A new Brussels airport rail access concept will offer for users not only time savings and attractive fares, but direct links to the cities of Liège (Cologne/Germany) and Antwerp (Rotterdam/Netherlands). Moreover, it will supply meaningful operating advantages and flexibility for the railway system in the 
Brussels area, thereby addressing the problems identified.

The Paris-Orly airport case is another specific one, as rail access relies on the operations of a nonconventional rail system. In the case of ORLYVAL the results are negative; this may be according to the specifics of the non-conventional rail system (as reduced volume supply) and to its operating features (high fare level with no season ticket use; link with change at a RER-station, with no significant travel time advantage under non-congested conditions); moreover, the (direct) coach and bus links (by Air France and RATP) are quoted as comfortable enough, so that only particular conditions, such as the punctuality (road traffic jam avoidance) may be of meaningful value when choosing the ORLYVAL connection; this advantage is however missing in the calculation, as there is still no accepted monetary value for reliability. Users' benefit remains therefore negative.

\section{CONCLUSIONS}

The seven case study results of airport rail access in Europe (Belgium; France; Germany; Switzerland) with a large spectrum of operating system backgrounds (city-centre to airport shuttle, suburban and national railway access and even HSR network access) as well as of technologies used (classical train, HSR, non-conventional system like VAL) can be summed up as follows:

- The effects overall taking into account the investment costs and the partial effects on the railways are positive for major (hub) airports, except for particular reasons (BRU \& ORY), and balanced or negative for the medium-sized airports analysed.

- The results show not only the impact of airport size, but also that of the access distance to the airport by rail, as users' benefit in time and fare savings have a significant role highlighting the benefits of access to as large a rail network as possible.

- The effects on public transport as a whole (all public transport companies at the airport, including taxi and parking operators) are negative.

As the calculation applies to the whole economic life of the new infrastructure, the value of the discount rate applied has a major impact on the results. The rates used where those generally applied for public works in the country of the case study, although calculations with other values were made for comparison purposes. The results were generally better when applying lower rates, much better in the case of Paris-CDG2, but almost stable in the cases of BRU and Paris-ORY.

There is also the issue of (still) non-monetarisable factors, such as comfort, which are related to personal perception and needs, are defined accordingly differently and have (case by case) an effect on transport mode choice. Certain gaps could be filled from stated-preference work undertaken by both 
railroads and governments in Europe, but these results have not yet been adopted for the official costbenefit guidelines used in Europe and where therefore not used.

Considering the conditions for success of rail access at airports, the seven case studies under review have already shown in Section 3 the (very) different backgrounds in terms of rail technology (classical trains; HSR; "non-conventional" like the VAL-System), types of airport rail access (city-centre shuttle; HSR or classical rail network at the airport), types of air traffic at the airport (hub or mediumsized), environment protection policies, (transport) "culture". All items may be correlated, but are not necessarily so, making it difficult to identify rules of success, as there are too few case studies for each main variable. It shows only, how carefully the matter has to be studied in terms of airport development, traffic forecasts, technical (rail access) project, rail operations, timing and period of economic life considered, and return on investment.

However some aspects can be recapitulated, starting with an obvious point:

- There is always a road to the airport; at the start, rail stations at airports unfortunately create additional access costs; but rail operating cost advantages may ease airport-related infrastructure cost concerns in the longer term.

- Rail systems are particularly successful with high volumes of transport and preferred in many cases for environmental reasons (compared to cars and planes); airport rail access is generally easier to realise wherever a rail network (close to the airport) in a rail-friendly "culture" already exists, allowing the use of season-tickets, realising gains in travel time (compared to (congested) road transport), serving a string of destination opportunities with frequent train departures.

- Airport rail access traffic volumes are of course expected to be in phase with air passengers volumes (landside), as access mode choice is primarily related to air passengers' and employees' choice and dependent on social habits generally expected in a country; this indicates that rail access can be expected to be successful at large (hub) airports, as shown;

- HSR especially is able to extend the catchment area of an airport, and doing so, potentially to replace feeder flights, freeing slots at (congested) airports.

- HSR is moreover able to generate gains in airport access time (and cost), an important component of the users' surplus in any CBA; this is effectively the case at Paris-CDG2, where HSR (TGV) generates alone a high user benefit with 1,3 Mio passengers a year (1998).

- In the case of airport shuttle services, the main rail station is a good downtown terminal in Europe (as a public transport connecting point, generally situated at the very centre of the city). As many air passengers are foreigners and/or elderly people, the airport access departure points should be well-known points, such as existing terminals.

- Limited to airport access only, other transport activities are expected to suffer from the rail challenge; however, a rail station at the airport is an additional one within the agglomeration (and the rail network as a whole) and may be an opportunity to develop a new (suburban) public transport interchange. 
- Such a new suburban public transport interchange will enhance the competitivness of the industrial and commercial enterprises located around the airport.

- Factors of convenience, perceived comfort, punctuality (fears of road traffic jams), may deliver further added value.

The authors wish to thank their collaborators in the COST 318 working group 4 (C. J. Dekoninck (Société Royale Belge des Ingénieurs et des Industriels), W. van Rompaey (Brussels International Airport Company), H.-G. Nüsser (Deutsche Versuchsanstalt für Luft- und Raumfahrt), M. Houée (French Ministry of Transport). The data was provided by CFF (F. Jomini, J.-P. Pilet, S. Anet, A. Vionnet, E. Petremand, J. Devanthéry, H. Scheurer), Swissair (L. Muller), AIG (Y.-D. Viredaz, R. Wüthrich), DB (Dr. R. Puschmann,), FAG (H. Fakiner), FVV (Dr. Hollborn), VVS (Dr.-Ing. Meier), SNCB (R. Cosyn, F. Pardens), AdP (B. Ohl-Millour), SNCF (B. Charabidze) and RATP (M. Barjanski).

The team in Zurich included also G. Abay, R. Gottwald, R. Schilling, O. Hintermeister and C. Dasen, whose contributions are gratefully acknowledged. All remaining errors are our own.

The authors want to thank K.W. Axhausen for his editorial support during the writing of the paper and his suggestions, which helped to improve the structure and presentation.

Abay, G. (1984a) Kosten-Nutzen-Analyse für Verkehrsinvestitionen, IVT-Bericht, 84/2, Institut für Verkehrsplanung, Transporttechnik, Strassen- und Eisenbahnbau, ETH Zürich, Zurich.

Abay, G. (1984b) SBB Flughafenlinie Zürich HB - Zürich Flughafen, Kosten-Nutzen-Analyse, IVTBericht, 84/3, Institut für Verkehrsplanung, Transporttechnik, Strassen- und Eisenbahnbau, ETH Zürich, Zurich.

COST 318 (1998) Interactions between High-Speed rail and air passenger transport, final report, DG 7, CEC, Brussels.

Dasen C. and J.-P. Widmer (1998) Dessertes ferroviaires des aéroports de Paris-Roissy (CDG2) et Orly, Analyse coûts-bénéfices, IVT-Bericht, 116/3, Institut für Verkehrsplanung, Transporttechnik, Strassen- und Eisenbahnbau, ETH Zürich, Zurich.

Deffke H., R. Ernst, W. Köppel and V. Meewes (1995) Kostenansätze für die volkswirtschaftliche Bewertung von Strassenverkehrsunfällen”, Preisstand 1995, Strasse und Autobahn, 46 (1) 23-33.

ECOPLAN (1992) Internalisierung externer Kosten im Agglomerationsverkehr, Bericht an das Nationalfonds-Programm 25, Ecoplan, Bern. 
Gottwald R., R. Schilling and J.-P. Widmer (1998) Bahnerschliessung Flughäfen Stuttgart und Frankfurt a.M., Kosten-Nutzen-Analyse, IVT-Bericht, 116/1, Institut für Verkehrsplanung, Transporttechnik, Strassen- und Eisenbahnbau, ETH Zürich, Zurich.

Gottwald R. and J.-P. Widmer (1998) Bahnerschliessung Flughafen Zürich. Kosten-Nutzen-Analyse (Up-date), IVT-Bericht, 116/4, Institut für Verkehrsplanung, Transporttechnik, Strassen- und Eisenbahnbau, ETH Zürich, Zurich.

Hintermeister O. and J.-P. Widmer (1998) Bahnerschliessung Flughafen Brüssel, Kosten-NutzenAnalyse, IVT-Bericht, 116/2, Institut für Verkehrsplanung, Transporttechnik, Strassen- und Eisenbahnbau, ETH Zürich, Zurich.

Mishan, E.J. (1975) Elemente der Kosten-Nutzen-Analyse, Campus Verlag, Frankfurt.

Widmer, J.-P. and G. Abay (1993) Desserte ferroviaire de l'aéroport de Genève-Cointrin, Analyse coûts-bénéfices, IVT-Bericht, 95, Institut für Verkehrsplanung, Transporttechnik, Strassen- und Eisenbahnbau, ETH Zürich, Zurich. 